\title{
Exploring the Relationship between Economic Growth and Employment in the Czech Republic and Belgium
}

\author{
Mansoor Maitah ${ }^{1}$, Daniel Toth $^{2} \&$ Elena Kuzmenko ${ }^{1}$ \\ ${ }^{1}$ Department of Economics, Faculty of Economics and Management, Czech University of Life Sciences Prague, \\ Czech Republic \\ ${ }^{2}$ Department of Economic Theories, Faculty of Economics and Management, Czech University of Life Sciences \\ Prague, Czech Republic \\ Correspondence: Mansoor Maitah, Faculty of Economics and Management, Czech University of Life Sciences \\ Prague, Kamycka 129, Prague 6 16921, Czech Rep. E-mail: Maitah@pef.czu.cz
}

Received: March 16, 2015 Accepted: April 23, $2015 \quad$ Online Published: June 26, 2015

doi:10.5539/res.v7n11p115 URL: http://dx.doi.org/10.5539/res.v7n11p115

\begin{abstract}
The paper addresses the issue of employment policy development and implementation in the selected European countries with a similar economic structure and population, namely the Czech Republic and Belgium. The existing approaches used by Ministries of Labour and Social Affairs are based either on drawing subsidies from EU structural funds within the frameworks of various Operational Programmes or direct job creation that is realized as a consequence of GDP growth. The retrospective observation of the development of such macroeconomic indicators as GDP per capita and employment rate in Belgium reminded us the Okun's law. This encouraged us to verify the inverted version of the latter and conduct a time series analysis with the use of ARIMA model. The conducted calculations revealed the existence of determined relationship between GDP per capita and employment rate, namely with GDP per capita increase by $2 \%$ corresponds to an increase in employment by $1 \%$. This relationship applies vice versa as well. The obtained result may be considered as an extension of the classical Okun's law theoretical framework. The main aim was to explore these relationships and on the basis of comparative analysis between macroeconomic indicators in the Czech Republic and Belgium to suggest recommendations aimed at development of employment policies.
\end{abstract}

Keywords: unemployment rate, employment policy, GDP per capita growth, Belgium, Czech Republic

\section{Introduction}

The unemployment being a structural problem is currently one of the most vital social and economic issues in the European Union. The importance of delivering stronger, lasting economic growth and associated with it job creation was emphasized both in the Lisbon Strategy and the EU's growth strategy for the coming decade "Europe 2020". According to these documents the proportion of employed population has to achieve up to $75 \%$ till the 2020 (Svatošová \& Kába, 2008). The proposed approaches in implementation of employment policies by the Ministries of Labour and Social Affairs should be based either on drawing subsidies from EU structural funds within the frameworks of various Operational Programmes or direct job creation that is realized as a consequence of GDP growth.

From the theoretical standpoint employment policies can be designed with the use of either ex-ante or ex-post approaches. Quantities defined in terms of measurements made at the end of the period in question are referred to as ex post; quantities defined in terms of action planned at the beginning of the period in question are referred to as ex ante (Statsoft, 2014). Thus, to be able to implement ex-ante approach it is necessary to conduct first a thorough retrospective, i.e. ex-post, data analysis.

With a purpose of effective employment policies' management it would be perfect to know in advance the expected relationship between selected macroeconomic indicators. In this regard theoretical framework of the American economist's Arthur Okun law becomes very interesting. In the twentieth century he developed the idea that if unemployment falls by $1 \%$, GDP grows by $2 \%$ and vice versa. Initially this assertion was empirically tested on the US economy in the mid. 1960 and it was valid only if the rate of unemployment is quite low, namely between $3 \%$ and $7.5 \%$. 
In the light of the Okun's law the present behaviour and relationship between GDP and unemployment/employment rate of the selected European countries has attracted our attention. The retrospective observation of the mentioned above indicators' development in Belgium led us to the assumption that there is a determined relationship between these indicators, somewhat reminding us the Okun's law, but not in its classical form. This finding encouraged us to verify the Okun's law in the new extended version, namely that an increase in GDP per capita by $2 \%$ initiates an increase in employment by $1 \%$. In this study our analysis will rest on the latter prerequisite with the use of time series analysis and ARIMA model. The aim of this study is to determine the future values of employment on the basis of the forecasted GDP per capita growth. Thus, the development of employment should evolve hand by hand with development of society's prosperity. At the same time having a particular structure of employment, the appropriate employment policies and facilitating means may promote the creation of new jobs, what consequently lead to an increase in the level of GDP per capita. Another objective is to propose possible changes in employment development tools and processes of their implementation.

\section{Methodology}

The methodology of the present study is composed of the following parts: a) calculation of Time Series with the use of ARIMA model, b) the analysis of Employment Economics and c) comparative trend analysis: trend function and exponential smoothing.

The data were obtained from the Eurostat database. Secondary data were processed by the statistical software SPSS IBM and Statistics.

\subsection{Time Series Regression Analysis Application}

There are three major goals of time-series analysis: 1) to forecast future values of a time series, using either previous values of just that one series, or values from other series as well; 2) to assess the impact of a single event on the analysed indicator; 3) to study causal patterns, by which we mean the effects of variables rather than events on a series.

The possible variants of trend functions are:

$$
\begin{array}{lc}
\multicolumn{1}{c}{\text { - Linear: }} & T_{t}=a+b t \\
\text { - Quadratic: } & T_{t}=a+b t+c t^{2} \\
\text { - Exponential: } & T_{t}=a b^{\prime} \\
\text { - Logarithmic: } & T_{t}=a+b l c g t \\
\text { - Cubic: } & T_{j}=a+b t+c t^{2}+d t^{3} \\
& \\
\text { - Inverse: } & T_{t}=a \mid \frac{b}{l}
\end{array}
$$

Selection of the trend function corresponds to the empirical description. Structural parameters of the trend function are estimated with the use of the least square method (LSM). When using this method the sum of squared deviations of the individual values of the time series from the trend has to be minimal:

$$
\sum_{i=1}^{n}\left(y_{i}-y_{i}\right)^{2}=\min _{1}
$$

where $\quad y_{t}, t=1, \ldots, n-$ the observed time-series values,

$$
y_{t}^{\prime}, t=1, \ldots, n \text { - the expected (theoretical) values of the monitored variables, }
$$

When applying mathematical and statistical modelling, the estimation of the structural parameters of the trend function becomes very important. At the same time it is necessary to include the stochastic component to the model, which is also used to reflect the degree of compliance. The latter, being frequently expressed by an index of determination, $I^{2}$, indicates how well data fit a statistical model. 


$$
I^{2}=1-\frac{\sum_{i-1}^{d}\left(y_{l}-y_{i}\right)^{2}}{\sum_{i-1}^{m}\left(y_{l}-w\right)^{2}}
$$

where is the arithmetic average of the empirical time series $\mathrm{y}_{1}, \ldots, \mathrm{y}_{\mathrm{n}}$.

Determination Index is a dimensionless number satisfying session:

$$
0 \leq I^{2} \leq 1
$$

The model better reflects the phenomenon under review when $I^{2}$ close to one. The closer the value of $I^{2}$ to zero, the less and less the constructed model is compliant to empirical data. It is therefore necessary to select a function which gives to the index of determination $I^{2}$ the maximum value. This enables functions best and most accurately to capture the real evolution of the studied phenomenon in the past and, therefore, it can be assumed that future facts may be reflected the same way (Hindls, Hronová, \& Seger, 2007). In addition to the index of determination we deal with the index of correlation:

$$
I=\sqrt{I^{2}}
$$

Here the same rules apply as above. The closer the value of correlation index to one, the better the model describes the evolution of time series patterns and vice versa. Suitability trend can also be assessed using the relative error of the forecast:

$$
\frac{\left(P_{1}-S_{1}\right)}{S_{1}} 100[\%]
$$

where $\mathrm{P}$ - the prediction value at time $\mathrm{t}$,

$$
S \text { - the fair value at time } t \text {. }
$$

The lower the value of the relative error, the more accurate the trend function is.

Modern statistical software for selection a suitable model trend has implemented additional criteria that rest on estimations of various modifications of mean errors:

The Mean Error (ME):

$$
M E=\frac{\sum\left(n_{1}-\eta_{i}\right)}{\eta}
$$

The Mean Squared Error (MSE):

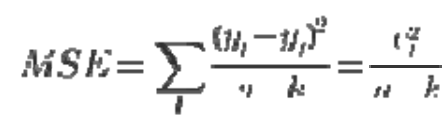

The Root Mean Squared Error (RMSE):

$$
A M S E-\sqrt{M S E}
$$

The Mean Absolute Error (MAE):

$$
M A E=\frac{1}{s} \sum_{i}\left|y_{l}-y_{i}\right|
$$


The Mean Percent Error (MPE):

$$
M P E=\frac{100}{*} \sum_{l}\left(\frac{t_{1}-y_{i}}{t_{1}}\right)
$$

The Mean Absolute Percent Error (MAPE) measures the size of the error in percentage terms:

$$
M A P H_{s}=\frac{1(9)}{\pi} \sum_{i}\left|\frac{b_{q}-b_{i}}{\nu_{i}}\right| .
$$

For comparison of alternative models, aiming at selection the most appropriate one (with the lowest values of these indicators), we computed all presented above measures.

Assessment of sub-models for different time series is based only on the relative degrees, which are variables independent of the units of measurement indicators examined, MPE and MAPE calculation parameters.

$$
\begin{aligned}
& b=\frac{\| \sum u_{i}-\sum \mu \sum n_{i}}{\left.n \sum x+2\right)^{2}} \\
& u=\frac{\sum m_{r}}{\pi}-b \frac{\sum x}{n}
\end{aligned}
$$

where $y_{i}$ - the values of the unemployment rate,

$$
\begin{aligned}
& \mathrm{n} \text { - the number of years studied } \\
& \mathrm{x} \text { - the time vector }(x=1,2,3, \ldots n) .
\end{aligned}
$$

The linear trend function can be embodied in the following form:

$$
y=a+b z
$$

which characterizes the course depending on the size of variable X Y.

The autoregressive integrated moving average (ARIMA) is the most frequently used model for forecasting time series. In our analysis the ARIMA (p, d, q) model serves as a filter that seeks to separate true signal from noise. Applying this approach we create extrapolation forecasts for the future values (Brdek \& Jírová, 1998). ARIMA forecasts are formed by equation for stationary time series, which are linear and represented by regression equations. "The ARIMA models are based on statistical concepts and principles and are able to model a wide range of time series patterns. Specifically, the three types of parameters in the model are: the autoregressive parameters $(p)$, the number of differencing passes $(d)$, and moving average parameters $(q)$. These models use a systematic approach to identify the known data patterns and then select the appropriate formulas that can generate the kind of patterns identified. The input series for ARIMA needs to be stationary, that is, it should have a constant mean, variance, and autocorrelation through time. Therefore, usually the series first needs to be differenced until it is stationary (this also often requires log transforming the data to stabilize the variance). The number of times the series needs to be differenced to achieve stationarity is reflected in the $d$ parameter. In order to determine the necessary level of differencing, one should examine the plot of the data and autocorrelogram. Significant changes in level (strong upward or downward changes) usually require first order non seasonal (lag=1) differencing; strong changes of slope usually require second order non seasonal differencing. Seasonal patterns require respective seasonal differencing. If the estimated autocorrelation coefficients decline slowly at longer lags, first order differencing is usually needed" (The Czech Statistical Office, 2013).

Applying this approach the following equations were tested:

$$
\begin{gathered}
\text { If } d=0: \quad y_{t}=Y_{t} \\
\text { If } d=1: \quad y_{t}=Y_{t}-Y_{t}-1 \\
\text { If } d=2: \quad y_{t}=\left(Y_{t}-Y_{t}-1\right)-\left(Y_{t}-1-Y_{t}-2\right)=Y_{t}-2 Y_{t}-1+Y_{t}-2,
\end{gathered}
$$

Thus, the general forecasting equation will be:

$$
\hat{y} t=\mu+F 1 y t-1+\ldots+F p y t-p-\theta 1 e t-1-\ldots-\theta q e t-q
$$


"However, one should keep in mind that some time series may require little or no differencing, and that over differenced series produce less stable coefficient estimates. At this stage (which is usually called Identification phase) one also need to decide how many autoregressive $(p)$ and moving average $(q)$ parameters are necessary to yield an effective but still parsimonious model of the process (parsimonious means that it has the fewest parameters and greatest number of degrees of freedom among all models that fit the data). In practice, the numbers of the $p$ or $q$ parameters very rarely need to be greater than 2. At the next step the parameters are estimated (using function minimization procedures), so that the sum of squared residuals is minimized. The estimates of the parameters are used in the last stage to calculate new values of the series (beyond those included in the input data set) and confidence intervals for those predicted values. The estimation process is performed on transformed (differenced) data; before the forecasts are generated, the series needs to be integrated (integration is the inverse of differencing) so that the forecasts are expressed in values compatible with the input data" (The Czech Statistical Office, 2013).

\subsection{The Okun's Law Application}

Regarding the Okun's law and its analytical application, one of its statistical relationship versions has the following simple form:

$$
\Delta u=\alpha-\beta \cdot y,
$$

where $\Delta u=U-U-1$ is a change in the unemployment rate,

$y=Y-Y-1 Y-1$ is the output growth rate,

$\alpha$ - the constant term,

$\beta$ - the slope parameter, which is usually referred to as Okun's coefficient.

The coefficient $\beta$ may be interpreted as follows: on average, a $1 \%$ increase in the output growth rate y is associated with a decrease in the unemployment rate by $\beta$ percent compared to the previous period (Ibragimov, Karimov, \& Permyakova, 2012).

\section{Results}

\subsection{Employment Policies and Employment Rates}

The strategy "Europe 2020" emphasizes the importance of effective employment policies in Europe for the next several years and sets the objective to achieve a 75\% employment rate by the end of 2020 (Svatošová \& Kába, 2008). Employment policies in the Czech Republic and Belgium are controlled by several institutions. Existing practical tools complement each other. On the national level the relevant ministries of Labour and Social Affairs are responsible for creation, development and management of employment concepts. Differences in these concepts can be found in the system and organization of relevant institutions. Belgium has more sophisticated hierarchical structure of labour offices. It employs 68,020 specialists in contrast to the Czech Republic, where just 25,753 specialists are employed. Taking into account that populations of these countries are approximately the same (Belgium-11.4 millions, the Czech Republic - 10.52 millions), it displays a huge difference. In both countries a wide range of supporting tools are offered to unemployed clients. Active Employment Policy in Belgium is slightly wider, focusing primarily on various financial subsidies and tax credits. Tools of passive employment policies do not differ too much. Since 2011 the Czech Republic began to reform the system of labour offices, which before 2010 was represented just by 77 offices. The Central Labour Office was formed in Prague. The main problematic feature of the Czech labour offices is that these offices do not provide a job; they mainly deal with unemployment benefits.

Accordingly to employment act No. 435/2006 Sb. certain groups of population are identified, paid more attention and assisted though mediation in the labour market. Risk groups of population are the subject of targeted assistance. Belgium, unlike the Czech Republic, used to increase the integration and cooperation of unemployed with the labour market consultancy on the basis of theirs residence. The main aim is to support people that belong to risk groups in getting employment at their homes, what contributes to saving in transport allowance or housing. The problem of unemployment in Belgium has a long history. However, currently the situation on the labour market in Belgium is much more stable than in the Czech Republic. The only problem, which still remains valid in Belgium, is that despite relatively high government spending on employment policy for many years the situation remains largely without radical changes.

If we look at the long-term development of employment in entire European Union (average value for the 28 member countries) and specifically in the Czech Republic and Belgium, we can see that Belgium represents 
values that are slightly below the EU's average. Over the period from 2000 till 2013 all values fluctuate with an increasing trend, which in case of Belgium equals to roughly 2 percentage points.

The graphs and calculations show that employment growth in the European Union as a whole and in the selected member countries was interrupted due to the World financial crisis in 2008. Also from this graph it is obvious that the recovery of the Czech Republic after the crisis years was quite rapid and more successful than in Belgium and the EU's in average. The main reason for that is a foreign direct investments inflow. Investments were mainly aimed at the manufacturing sector contributing as a result to a slight increase in the number of new jobs in the secondary sector. The number of unemployed graduates of secondary schools and universities remains more or less the same due to available possibilities to gain jobs in the tertiary sector or in public administration, respectively.

Ibragimov et al. (2012) deals with an indicated problematic more deeply and asserts that there are a number of sustainable factors affecting the value of unemployment rate (expressed in the coefficient $\beta$ ), such as labour market institutions (e.g. legislative employment protection, unemployment benefits, employment contracts and wage flexibility) and episodic factors manifested in the economic and financial crises, changes in housing prices, trade shocks, policy changes and economic and financial uncertainty, among others. Thus, the coefficient $\beta$ and the effects caused by the mentioned above factors usually vary in different stages of economic development, as well as in phases of recession and recovery (Gabrisch \& Buscher, 2006, World Economic Outlook, 2010). The differences in the values of the coefficient $\beta$ across countries and over time are important because they reflect the influence of several key factors on the dynamics of unemployment and labour markets.

According to the estimates of Okun's model for Russia obtained in the project by Ibragimov et al. (2012), "on average, a $1 \%$ increase in the quarterly GDP growth rate in this country is associated with a decrease in the unemployment rate by $0.06 \%$ compared to the previous quarter." "The inflexibility of the Russian labour market leads to persistence in changes of the unemployment rate and to absence of the immediate response of the latter to changes in output." (Akhundova, Korovkin, \& Korolev, 2005) The shadow component of resource and goods markets has been playing a major role in the production of wealth in Russia. It includes, among others, import and export of unrecorded labour, shadow wages as well as shadow production and allocation of goods (Ibragimov, Karimov, \& Permyakova, 2012).

Table 1. Employment rates over the years 2000 to 2013 in Belgium, the EU and the Czech Republic

\begin{tabular}{lllllllllllllll}
\hline Years & $\mathbf{2 0 0 0}$ & $\mathbf{2 0 0 1}$ & $\mathbf{2 0 0 2}$ & $\mathbf{2 0 0 3}$ & $\mathbf{2 0 0 4}$ & $\mathbf{2 0 0 5}$ & $\mathbf{2 0 0 6}$ & $\mathbf{2 0 0 7}$ & $\mathbf{2 0 0 8}$ & $\mathbf{2 0 0 9}$ & $\mathbf{2 0 1 0}$ & $\mathbf{2 0 1 1}$ & $\mathbf{2 0 1 2}$ & $\mathbf{2 0 1 3}$ \\
\hline EU & - & - & 62.3 & 62.5 & 62.9 & 63.4 & 64.3 & 65.3 & 65.7 & 64.5 & 64.0 & 64.1 & 64.1 & 64.1 \\
Czech Republic & 65.0 & 65.0 & 65.4 & 64.7 & 64.2 & 64.8 & 65.3 & 66.1 & 66.6 & 65.4 & 65.0 & 65.7 & 66.5 & 67.7 \\
Belgium & $62 ., 1$ & 62.8 & 63.0 & 63.9 & 63.7 & 63.7 & 63.6 & 64.3 & 64.8 & 64.0 & 63.9 & 63.8 & 63.9 & 64.1 \\
\hline
\end{tabular}

Source: Eurostat, the authors processing

The following below charts were generated with the use of STATISTICA analytics package. The necessary raw data were taken from the Eurostat database and were represented in quarterly form from 2007, Q1, till 2014, Q3. Therefore, we have got 31 local time series. The analysing data visualization is given in the charts 1 and 2, which are enriched with linear curve, determination index and regression equations. 


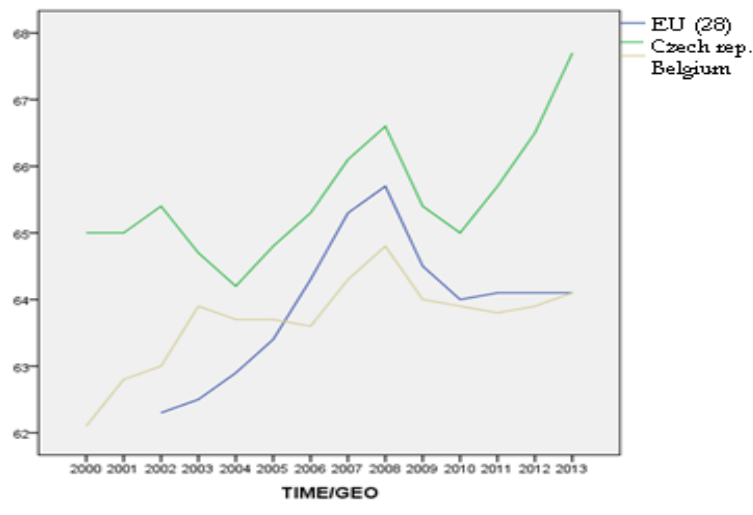

Graph 1. Employment in Belgium, the Czech Republic and the EU

Source: Eurostat, the author's processing.

The graphs reflect factual data developments from the past (the blue curves) along with the forecast of development in future, i.e. predictions (the red curves). The level of confidence is approximately $70 \%$ (green curves).The Strength of statistical evidence, being rest on the Chi-square goodness-of-fit test, provided us with the following outcome: 0.4211 , probability $\alpha=0.05$.

To begin with it is necessary to analyse the current situation in Belgium with regard to unemployment. Currently, the overall unemployment rate in Belgium around is $8.5 \%(\mathrm{Q} 3,2014)$. At the beginning of the period under study (2007, Q1) this value was 7.8\%. From the chart 1, we know that for the last 31 reporting periods the unemployment rate was more or less stable with the values around $8 \%$.In comparison with the European benchmark Belgium ranks among the countries with an average unemployment rate. This allows us to suggest that expected values of unemployment in future remain roughly the same, i.e. up to the approximate level of $8.5 \%$.

For the construction of the next two charts the data were taken from the Eurostat. Data were adjusted according to the desired size. Individual years were divided into quarters for detailed analysis. Analysed indicators are the Belgian Gross Domestic Product per capita and the EU's 28 average GDP per capita in PPP, which is equal to 100 .

If the index for a country is higher than 100, it means that the per capita GDP of the country is higher than the EU's 28 average and vice versa. Chart 3 shows the evolution of GDP per capita in Belgium. The time period under investigation is from Q1 2007 to Q2 2014. The largest decline in per capita GDP was reached in Q3 2008-Q2 2009. The sharp increase was monitored in Q2 2010.

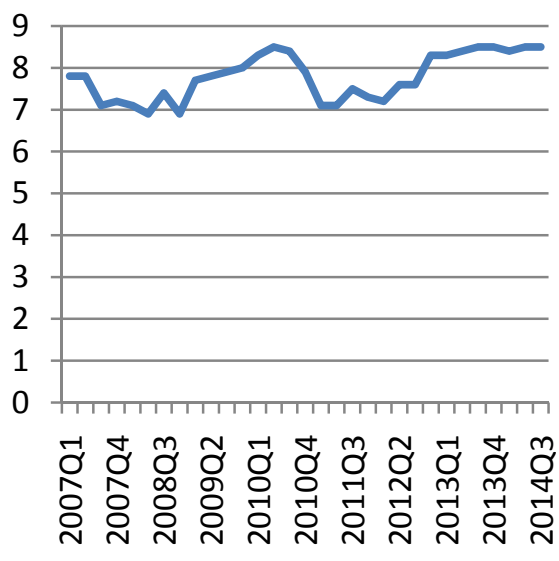

Chart 1. Development of unemployment in Belgium Source: Eurostat, the author's processing

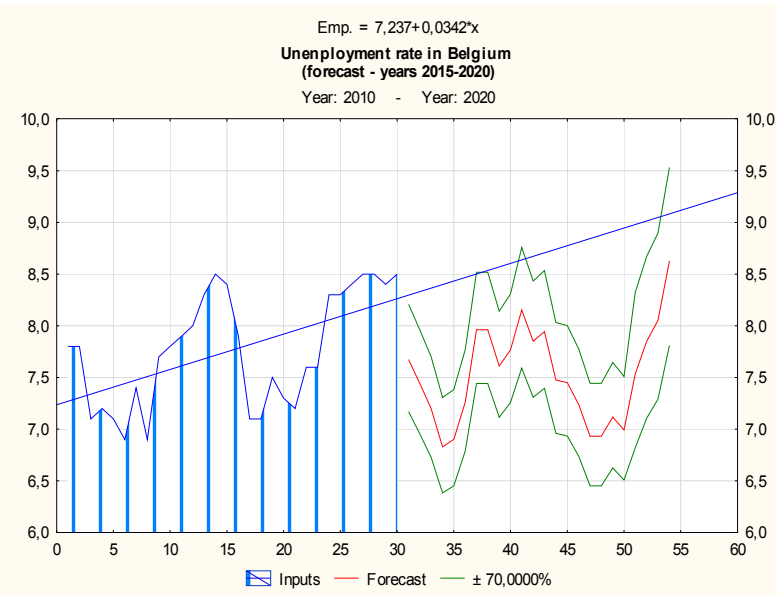

Chart 2. Forecast of unemployment for the period until the end of 2020

Source: Eurostat, the author's processing 
The chart 4 shows the future evolution of GDP per capita in Belgium. Specifically, the data cover period from the third quarter of 2014 (case no. 31) till the 4th quarter of 2020 (case no. 56). For each prediction the standard deviation and $70 \%$ confidence is assembled.

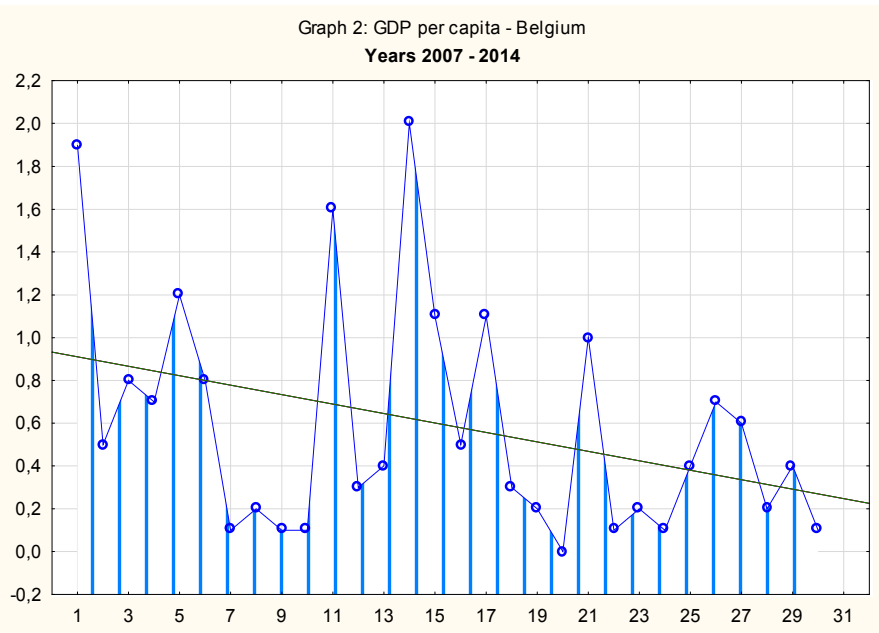

Chart 3. The line chart GDP per capita 1 st quarter 2007 to 2 nd quarter 2014

Source: Eurostat, the authors processing

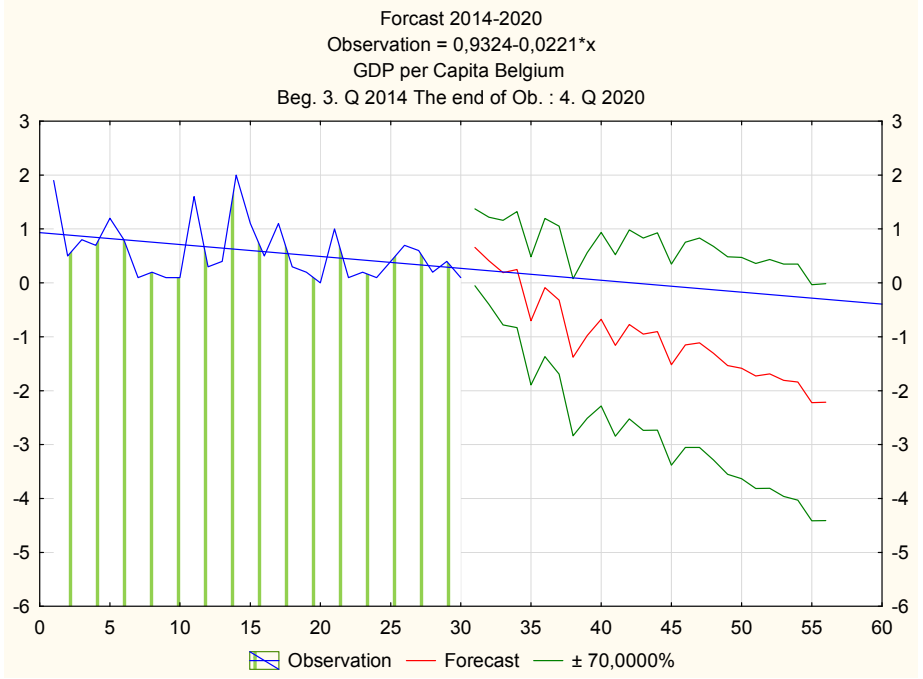

Chart 4. Forecast of per capita GDP of Belgium during Q3 2014 to Q4 2020

Source: Eurostat, the authors processing

The Czech Republic experiences the decline in GDP per capita since 2013. It is not the case of Belgium. Belgium is well above average values of 28 countries in the European Union. At the end of 2012 Belgium's value fell below the average, but it still achieves positive values. The penultimate part focuses on the analysis of the strength test. The strength test is assessed here by just three tests, namely determination coefficient, correlation, and chi-square test of variance. The coefficient of determination indicates that the resulting function explains $99.28 \%$ of the variation in the dependent variable (GDP per capita). In case if this values greater than $75 \%$ it is taken as sufficient explanation (Toth, 2013). Also the Fisher's t-test of significance was implemented. The recommended minimum value for strength test was set 0.7 (the second type of error probability is more than $30 \%$ ). The result is that the correlation with values of 0.2 is therefore statistically significant (for future development). The calculated power of dissipation achieves only 0.4211 , what means that the reality does not match the expectations too.

\subsection{Comparison}

Belgium, as well as the Czech Republic, is a liberal open economy that is dependent on foreign markets and on the development of the world economy as a whole and the economic situation in the EU. Belgium is among the World's ten largest exporters (export values are 3 times more than that of the Czech Republic). Three quarters of GDP are represented by mainly manufacturing - production of steel, automobiles, chemicals, pharmaceuticals, textiles. Among factors that negatively affect Belgium GDP are unit labour costs that grew faster than labour productivity. This led to a decline in the competitiveness of Belgian exports. The aging population becomes another long-term strategic problem. In response to this in Belgium was created a special fund to pre-finance the costs of aging population, from which the government has committed to contribute $0.3 \%$ of GDP in 2010 to $1.5 \%$ of GDP in 2013 and etc. The Belgium economy until 2008 demonstrated the long-term and stable growth. Thanks to the policy of a balanced budget there was a reduction of public debt to GDP ratio (Hindls, Hronová, \& Seger, 2007). Due to the financial and economic crisis, Belgium failed to create a budget surplus to finance the Fund for aging population and as a result the economy weakens (Brčák \& Sekerka, 2010, Halásková, 2008). The peak of the financial crisis consequences was reached in 2011 and negatively affected all macroeconomic indicators. The banking system was heated the most (one of the biggest bank Dexia). Since 2012, the Belgian economic indicators are falling again, for example GDP up by $0.2 \%$. As a result Belgium competitiveness was declined, weakening export growth, which Belgium is critically dependent on. Inflation reached values that are 
higher than the surrounding lands have. The surrounding lands economic development has also negatively affected Belgium in 2012-2014 years. State budget deficit due to austerity measures becomes less; however the government debt is at $100 \%$ of GDP, the structure of which is represented in a relatively safe area. This pushes the investors in confidence that Belgian debt is high-quality. "The increase in GDP of six largest markets in the euro area is expected to be mainly associated with export growth. Domestic consumption in 2013 by the European Commission increased only slightly, mainly due to low increase in wages, the continuing uncertainty and continued growth of savings at the expense of consumption. According to the National Reform Plan the Belgian economy should grow on average by about $2 \%$ per year by 2020 (Šrédl, 2006). The future economic development is difficult to estimate because the weights and the effects of the main influencing factors are unclear. (Toth, Maitah, \& Stefkova, 2014, Maitah, Hayat, Malec, \& Eldeeb, 2014, Federal Planning Bureau, 2011)

\section{Conclusions}

One of the priority aims of the European Union till the 2020 is the employment development. Expectations are very optimistic, but the reality a little bit differs, demonstrating a slight decline in employment rates. In both countries under analysis we observed stagnant GDP per capita. According to the calculated data the level of employment in Belgium will reach $61.92 \%$ in 2020, while the European Union's planed rate is set on the $75 \%$ for all Member States. Belgium aims to achieve at least $73.8 \%$ employment rate in 2020. The calculations revealed that forecasted data are not far from the strategic objectives. The main reason for that is that Belgium is trying to balance macroeconomic indicators, focusing on the development of GDP per capita with the purpose of regional employment developing. Given that the future development of the Belgian employment is influenced mainly by foreign trade, it is likely that future employment development will be related to the increase in the share of foreign exports in nominal GDP. The model that was used didn't include foreign trade component. The resulting prediction can probably be different. According to the National Reform Plan till 2020, the Belgian economy should grow by less than $2 \%$ per year. According to the calculation and prediction the GDP in 2020 will fall slightly (Halásková, 2008; Eurostat, 2013). The result of the conducted analysis revealed also another aspect. If GDP per capita in Belgium continue to decline it will have a negative impact on employment manifested in the relative increase in unemployment. Employment growth by one percentage point should be based on a two-percentage points growth in GDP per capita. The forecast revealed also an inverse impact, namely that the decline in GDP per capita of about two percent will cause a reduction in employment by one percent. Belgium, according to calculations, will have to revise the strategy for developing employment by the end of 2020, because the target is to meet the 75\% employment rate (Federal Planning Bureau, 2011, The Czech Embassy in Brussels, 2014, The Czech Statistical Office, 2013). The relationship between unemployment rate and GDP is another area of research. Inspired by the law of American economist Arthur Okun, who in the middle of the twentieth century developed the idea that if unemployment falls by $1 \%$, GDP grows $2 \%$, we decided to verify this relationship empirically on the Belgium data. However, this law was initially designed and empirically valid for the US economy. Furthermore, the Okun's law is true only if the unemployment rate is in the range from 3 to $7.5 \%$. The present study revealed the existence of determined relationship between GDP per capita and employment rate, namely with GDP per capita increase by $2 \%$ corresponds to an increase in employment by $1 \%$. This relationship applies vice versa as well). The obtained result may be considered as an extension of the classical Okun's law theoretical framework (Toth, 2010). Therefore, we should focus on the development of employment developments wealth of the country as a whole. Increased GDP per capita should strengthen household consumption, including export activities. This should lead to the long-term development of employment in the Czech Republic, in a similar manner as in the case of Belgium.

Countries within the EU, like the Czech Republic, resolve stagnation (or slight increase) in employment by means of the EU structural policy. However, the recommendation is to ensure the economic and fiscal conditions for GDP per capita growth, what will cause the multiplier effect manifested in new job creation. Calculations and projections indicate that the multiplier effect of GDP per capita growth on employment rate may be implemented in future. Also on the basis of forecasts for Belgium a positive trend of employment growth is expected. Therefore, one of the recommendations for the Czech Republic's economic policy is to follow the Belgium's example.

\section{Acknowledgements}

This paper was partially prepared on the selected materials of the research project "Ropa-hybná síla, či brzda institucionálních změn a hospodářského rozvoje v Rusku?" ("Whether the crude oil is a driving or braking force for institutional changes and economic development in Russia") performed within the internal grant No.11110/1312/113146, provided by IGA of the FEM, CULS. 


\section{References}

Akhundova O. V., Korovkin A. G., \& Korolev I. B. (2005). Relationship between GDP dynamics and unemployment: Theoretical and practical aspect. In A. G. Korovkin (Ed.), INP RAN Scientific Works (pp. 471-497). (In Russian)

Brčák, J., \& Sekerka, B. (2010). Makroekonomie. Plzen: Aleš Čeněk.

Brdek, M., \& Jírová, H. (1998). Sociální politika v zemích EU a ČR (1st ed.). Praha: CODEX.

Eurostat. (2014, April 13). http://epp.eurostat.ec.europa.eu/portal/page/portal/eurostat/home/

Federal Planning Bureau. (2011). National Reform Programme Belgium 2011. Retrieved from http://www.be2020.eu/uploaded/uploaded/201105260843540.NRP_2011_en.pdf

Gabrisch, H., \& Buscher, H. (2006). The relationship between unemployment and output in post-communist countries. Post-Communist Economies, 18, 261-276. http://dx.doi.org/10.1080/14631370600881804

Halásková, R. (2008). Politika zaměstnanosti (1st ed.). Ostrava: Ostravská univerzita v Ostravě.

Hindls, R., Hronová, S., \& Seger, J. (2007). Statistika pro economy (8th ed.). Praha: Professional Publishing.

Ibragimov, M., Karimov, J., \& Permyakova, E. (2012). Unemployment and Output dynamics in CIS countries: Okun's Law revisited (Working paper No E13/04). Kiev: Economics Education and Research Consortium.

Maitah, M., Hayat, A., Malec, K., \& Eldeeb, O. (2014). The Impact of Foreign Direct Investments on Employment in the Czech Republic. Research Journal of Applied Sciences, 9, 1001-1008.

Šrédl, K. (2006). Ekonomie \& teolog. Brno: L. Marek.

Statsoft. (2014). Time Series Analysis: ARIMA model methodology. Retrieved from http://www.statsoft.com/textbook/time-series-analysis\#ageneral

Svatošová, L., \& Kába, B. (2008). Statistické metody II (1st ed.). Praha: Česká zemědělská univerzita v Praze.

The Czech Embassy in Brussels. (2014, November 28). Belgie: Ekonomická charakteristika země. Retrieved from http://www.businessinfo.cz/cs/clanky/belgie-ekonomicka-charakteristika-zeme-19324.html\#sec2

The Czech Statistical Office. (2013). Evropský srovnávaci program. Retrieved from http://www.czso.cz/csu/redakce.nsf/i/evropsky_srovnavaci_program

Toth, D. (2010). Lisabonská strategie a strategie Evropa 2020. Praha: Powerprint.

Toth, D. (2013). Ekonomie a management sociálniho rozvoje. Praha: Galileo.

Toth, D., Maitah, M., \& Stefkova, M. (2014). Comparative Research of Youth Employment in France and the Czech Republic. Research Journal of Applied Sciences, 9, 1009-1015.

World Economic Outlook. (2010). Chapter 3: Unemployment dynamics during recessions and recoveries: Okun's law and beyond. Retrieved from http://www.imf.org/external/pubs/ft/weo/2010/01/pdf/c3.pdf

\section{Copyrights}

Copyright for this article is retained by the author(s), with first publication rights granted to the journal.

This is an open-access article distributed under the terms and conditions of the Creative Commons Attribution license (http://creativecommons.org/licenses/by/3.0/). 